\title{
Proportional implies relative: A typological universal
}

\author{
Elizabeth Coppock, Golsa Nouri-Hosseini, Elizabeth Bogal-Allbritten \& Saskia Stiefeling*
}

\begin{abstract}
We give evidence from a geographically, genetically, and typologically diverse set of languages (drawn from 26 different language families and every continent) for the following typological universal: Regardless of the morphosyntactic strategy used by a language to form superlatives, if superlative morphosyntax can be applied to 'much' or 'many', then the result can be used to express a relative reading (as in Hillary has visited the most continents (out of everyone)) but not necessarily a proportional reading (as in Hillary has visited most of the continents). Thus, no language deploys the regular superlative of 'much'/'many' for the proportional but not the relative reading. We also give a rough estimate of how rare proportional readings for quantity superlatives are: about $10 \%$. Nevertheless, we show that proportional readings arise with a diverse set of strategies for forming superlatives.
\end{abstract}

Keywords. Superlatives, quantity words, typology

1. Introduction. This paper considers the crosslinguistic semantics of superlative forms of quantity words, exemplified in English by many, much, few and little. In English, the superlative forms of much and many permit either a proportional interpretation, as in (1), or a relative interpretation, as in (2).

(1) Most of the students passed.

[PROP]

John answered the most questions correctly.

[REL]

(1) implies that roughly more than half of the students passed, whereas (2) does not imply that John answered more than half of the questions correctly; (2) is true as long as John answered more questions than anyone else, even if that number is less than half the number of questions. The relative reading is focus sensitive (Szabolcsi, 1986), and in this case, focus falls most naturally on John, so the truth of the sentence depends on the alternatives to John, and in particular, how many questions they answered correctly.

According to Hackl (2009), the two interpretations of quantity superlatives have semantic analyses which are parallel to the absolute (3) and relative (4) interpretations of ordinary gradable adjectives.

(3) The smartest student passed.

(4) Of the students, John gave the best answer.

In (3), the superlative adjective smartest receives an absolute interpretation: the smartest student refers to the student who is smarter than all other students. In (4), by contrast, the superlative best

${ }^{*}$ We would like to thank the audience at LSA for the helpful feedback we received on this work, and our many kind language consultants for their generosity with their time. This research was carried out under the auspices of the Swedish Research Council project 2015-01404 entitled Most and more: Quantity superlatives across languages awarded to PI Elizabeth Coppock at the University of Gothenburg. Authors: Elizabeth Coppock, University of Gothenburg (eecoppock@gmail.com), Golsa Nouri-Hosseini (golsa.nouri.h@gmail.com), Elizabeth Bogal-Allbritten (elizabethba@gmail.com)\& Saskia Stiefeling (saskiastiefeling@gmail.com). 
receives a relative interpretation: the best answer does not refer to the answer that is better than all others; in fact, it arguably does not even refer to a particular entity (Szabolcsi, 1986; Coppock $\&$ Beaver, 2014). For example, as Szabolcsi (1986) observed, superlatives of relative readings can occupy positions that are normally restricted to non-definite noun phrases, such as the complement of have, with a relational noun:

John has the $*($ nicest $)$ sister.

And in Swedish, the contrast between relative and absolute readings is distinguished morphologically; the following example, without definiteness-marking, has only a relative reading, and no absolute reading (Teleman et al., 1999):
Gloria säljer god-ast glass.
Gloria sells delicious-SPRL ice_cream
'Gloria sells the most delicious ice cream. [REL]'

With definiteness-marking ( $\underline{\text { den }}$ godaste glass $\underline{\text { en }}$ ), an absolute reading becomes available. So the absolute/relative distinction is substantive insofar as it can have both syntactic and morphological consequences, and Hackl's idea is that this distinction corresponds to the distinction between proportional and relative readings of quantity superlatives.

Hackl's theory (discussed in more detail in Section 3) predicts that any instance of the superlative form of many - namely most - will permit a proportional reading in addition to a relative reading. For Hackl, the proportional reading is a direct consequence of many occuring in a superlative construction. The superlative form of many should therefore have a proportional reading in any language where superlatives of adjectives have absolute readings.

There exist many known counterexamples to this prediction, however. Bulgarian is one example (Pancheva \& Tomaszewicz, 2012; Živanović, 2006; Dobrovie-Sorin \& Giurgea, 2015). In (7), the superlative prefix is naj- and the word for many is mnogo. The superlative form of many in (7) only has a relative interpretation: it means that Maria read more articles than anybody else. This sentence lacks a proportional interpretation: (7) cannot be used in the same contexts as the English sentence Maria read most of the articles.

(7) Maria pročete naj-mnogo-(to) statii

[Bulgarian]

Maria read SPRL-many-the articles

'Maria read the most articles [REL only].'

French provides another counterexample to this prediction (Dobrovie-Sorin \& Giurgea, 2015). In (8), we see that the regular strategy for forming a superlative - the definite article plus plus 'more' - is used with a relative interpretation. However, this superlative construction does not have a proportional interpretation. The sentence in (9) cannot be used in the same contexts as the English sentence Most swans are white; the structure in (10) is used instead to express a proportional superlative meaning.

(8) C'est Jean qui a lu le plus de livres.

[French]

it:is Jean who has read the more of books

'It's John who has read the most books [REL only].' 
(9) *Le plus de cygnes sont blancs.

the more of swans are white
La plupart des cygnes sont blancs.
the majority of.the.PL swans are white
'Most swans are white [PROP].'

These initial data suggest that in comparison with relative readings, proportional readings of quantity superlatives are typologically marked. Whenever a language allows proportional readings for a superlative form of many or much, that language also allows relative readings for the same expression. The reverse is not true, however: French and Bulgarian allow relative readings for quantity superlatives but do not allow proportional interpretations. We frame this idea as the implicational universal in (11).

\section{Proposed Universal: Proportional $\Rightarrow$ Relative}

If a superlative form of 'many' or 'much' has a proportional interpretation, then it also has a relative interpretation.

Table 1 summarizes the predictions.

Table 1: Attested and unattested patterns

\begin{tabular}{lll}
\hline & Proportional: yes & Proportional: no \\
\hline Relative: yes & English, Swedish & Bulgarian, French \\
Relative: no & IMPOSSIBLE & POSSIBLE (?) \\
\hline
\end{tabular}

Thus, we predict that there are languages which allow both relative and proportional interpretations for the superlative form of many/much, as indeed we know there are; languages of this type include English and Swedish. We also predict there to be languages in which quantity superlatives allow relative, but not proportional, readings; languages of this type include Bulgarian and French. We might also find languages in which the superlative form of many/much allows neither relative nor proportional readings. (We might also imagine such languages not to exist; a stronger hypothesis would be that any superlative of many has at least a relative interpretation, but that is going beyond the hypothesis that is to be tested here.) Crucially, however, we predict that there are no languages which allow proportional readings for the superlative of many/much but do not allow relative readings for the same expression.

The paper proceeds as follows. Section 2 summarizes the elicitation materials and data collection methodology used in the study. Section 3 presents the key empirical findings and discusses their significance. Section 4 presents data from several languages of special interest. Section 5 concludes and considers directions for future work.

2. Method. We propose to call the method that we used BROAD SAMPLE SEMANTIC FIELDWORK. It involves a broad sample of languages and semantic fieldwork on a targeted issue (quantity superlatives in this case). We have touched on 26 language families and about 100 languages 
across all continents. Table 2 lists one language from each subfamily that we investigated, by continent.

We used an online translation survey as a way to initiate data collection. The translation questionnaire is a short story that contains the constructions of interest, including both count and mass nouns, most and fewest, and regular superlatives. The full story is given in Appendix A; key example sentences for the purposes of testing the universal in question are shown below. For quality superlatives, these sentences target absolute (12) and relative (13) interpretations. For quantity superlatives, they target proportional (14) and relative (15) ones.

Mom bakes the most delicious cookies in the world.

[Quality - absolute]

(13) I'm not the one in the family with the thinnest waist.

[Quality - relative]

(14) Most of the kids in my school like to play music.

[Quantity - proportional]

(15) a. I am the member of our family who eats the most cookies.

b. Among the kids in my school, I'm the one who plays the most instruments.

[Quantity - relative]

Variants of these sentences will appear in the translations of elicited sentences.

We then used the answers we received as a basis for follow-up questions. To construct followup questions, we modified example (15-a) and presented it in an unambiguously proportional context, to check whether the strategy used for relative readings could be used to express a proportional interpretation. For example, German speakers sometimes used am meisten for the relative reading:

(16) Ich bin das Mitglied unserer Familie, das am meisten Plätzchen isst.

I am the member our family that on.the much.SPRL cookies eats

'I am the member of our family who eats the most cookies.'

To test whether this strategy could be used to express a proportional reading, we asked the following:

Suppose you are home alone one weekend and you bake a batch of 10 cookies. When they come out of the oven, you are extremely hungry, so you eat 7 of them. Only three are left. Later you're telling me what happened, and you say:

Ich habe am meisten Plätzchen gegessen.

a) Is this sentence something a native speaker of German would say?

b) Is it appropriate to use in this context?

The answer to (b) is clearly no in this case (even though the sentence itself is grammatical), which shows that am meisten does not have a proportional reading.

The number of speakers who participated in the online translation survey varied from language to language; we aimed for five, but the actual number varied between one and 15 . A subset of these speakers responded to follow-up questions.

We coded each language according to certain characteristics. We first coded languages for basic information about how comparatives and superlatives are formed. For comparatives, we 


\begin{tabular}{|c|c|c|c|}
\hline Macro-area & Family & Subfamily & (Language) \\
\hline \multirow[t]{19}{*}{ Eurasia } & Basque & Basque & \\
\hline & Indo-European & Albanian & \\
\hline & & Balto-Slavic & Macedonian \\
\hline & & Celtic & Irish \\
\hline & & Germanic & Swedish \\
\hline & & Indo-Iranian & Persian \\
\hline & & Italic & French \\
\hline & Turkic & Common Turkic & Turkish \\
\hline & Uralic & Finnic & Finnish \\
\hline & Kartvelian & Georgian-Zan & Georgian \\
\hline & Nakh-Daghestanian & Daghestanian & Lezgian \\
\hline & Sino-Tibetan & Mahakiranti & Newar \\
\hline & Dravidian & South Dravidian & Tamil \\
\hline & Tai-Kadai & Kam-Tai & Thai \\
\hline & & Greek & \\
\hline & & Hungarian & \\
\hline & Austroasiatic & Khmer & \\
\hline & Japonic & Japanese & \\
\hline & Koreanic & Korean & \\
\hline \multirow{8}{*}{ Africa } & Afro-Asiatic & Cushitic & Somali \\
\hline & & Semitic & Arabic \\
\hline & & West Chadic & Hausa \\
\hline & Atlantic-Congo & North-Central Atlantic & Wolof \\
\hline & & Volta-Congo & Yoruba \\
\hline & Eastern Sudanic & Nubian & Kenuzi-Dongola \\
\hline & Mande & Western Mande & Vai \\
\hline & Nilotic & Western Nilotic & Lango \\
\hline \multirow[t]{2}{*}{ Papunesia } & Austronesian & Nuclear Austronesian & Javanese \\
\hline & Gunwinyguan & Marne & Kunbarlang \\
\hline \multirow[t]{5}{*}{ North America } & Athapaskan-Eyak-Tlingit & Athapaskan-Eyak & Navajo \\
\hline & Iroquoian & Cherokee & \\
\hline & Mayan & Core Mayan & Yucatec Maya \\
\hline & Otomanguean & Eastern Otomanguean & San Juan Guelav \\
\hline & Salishan & Interior Salish & Interior Salish \\
\hline \multirow[t]{2}{*}{ South America } & Aymara & Nuclear Aymara & \\
\hline & Quechuan & Quechua II & Cochabamba Quechua \\
\hline
\end{tabular}

Table 2: Language sample 
followed Bobaljik (2012) in using two parameters, one for the general strategy for forming comparatives (CMPR-TYP), and one for the marking associated with the gradable predicate (CMPR). The general strategies for CMPR-TYP included:

STND: Standard comparative (e.g. English She is taller than Bill, where than introduces the standard of comparison).

EX: Exceed comparative (e.g. Yoruba $O$ tobi ju $u$, lit. 'He big exceed him'; Stassen 1985)

CNJ: Conjoined comparative (e.g. Washo 'The man is tall, the woman is not tall'; see Bochnak 2015)

The parameter for the marking associated with the gradable predicate (CMPR) had the following possible values:

M: Morphological expression of comparative (e.g. English -er)

PERIPH: Comparative is expressed analytically with a free element (e.g. Turkish Mehmet Ali'den daha zengin 'Mehmet is richer than Ali', lit. 'Mehment Ali-from more rich'1).

ZERO: Comparative is not marked (e.g. Lezgian Awar č'al lezgi č'al.a-laj četin ja 'Awar is more difficult than Lezgian', lit. 'Awar language Lezgian language-from.on difficult is'; Haspelmath 1993).

For superlatives (SPRL), we used a categorization scheme combining the work of Bobaljik (2012) and a Gorshenin (2012). The categories we used are as follows (category labels taken approximately from Bobaljik 2012, with the exception of 'ANY'):

M: Morphological superlative marker (e.g. English tall-est). Following Bobaljik (2012), we classify languages in this way if a morphological strategy is available for at least some adjectives.

PERIPH: Periphrastic superlative marker, in some cases optional (e.g. Turkish en leziz 'most delicious').

CMPR+DEF: Superlative indicated via definiteness alone (e.g. French la plus belle 'the more beautiful').

CMPR: No formal distinction between comparative and superlative. Irish has been argued to be a language of this kind (Bobaljik, 2012).

CMPR+ALL: Superlative indicated with 'of/than all' (e.g. Russian vyš-e vse-x 'tall-er all-of').

CMPR+ANY: Superlative indicated with 'of/than some/any' (e.g. Khmer klang ciang kee 'strong exceed someone', where ciang 'exceed' is the regular strategy for forming comparatives and kee 'someone' is the indefinite standard). This can be seen as a variant of the 'ALL' strategy with an indefinite rather than universal standard, and can be glossed as 'more than anyone'. 2

VERY: Superlatives are translated using an intensifier (e.g. Maori teitei rawa atu 'tall indeed away').

ABS: There is only an 'absolute' (i.e. 'elative') superlative. (We have no examples of this; see Bobaljik 2012.)

\footnotetext{
${ }^{1}$ http: / / www.turkishlanguage.co.uk/adjcomparison.htm

${ }^{2}$ Gorshenin (2012) categorizes this strategy as 'absolute comparison superlative with an indefinite pronoun with universal reference' ('Type A/Indef languages').
} 
OTHER: Either no superlative is reported, or some other strategy is used (e.g. in Vietnamese where the superlative is reportedly indicated aspectually).

NONE: No superlative is reported (despite availability of full grammar).

Each language was assigned one of these codes, although many languages use multiple strategies. The code is intended to represent the language's 'primary strategy', to use Gorshenin's (2012) term, and always corresponds to the strategy that is used with quantity superlatives. The specific codes assigned to each language were primarily taken from secondary literature on the languages, including Bobaljik (2012), Gorshenin (2012), as well as grammars, and were in some cases overridden by our own fieldwork.

For quantity superlatives, we then determined on the basis of the translation questionnaire and follow-up questions whether that basic strategy for forming superlatives, combined with many or much, allowed (i) a proportional interpretation and (ii) a relative intepretation. That means that there are four possible language types: YES-YES, YES-NO, NO-YES, and NO-NO. The prediction is that we should not find any YES-NO languages, with a proportional interpretation but not a relative one for quantity superlatives.

3. Results. Figure 1 is a representative sample of the languages that we investigated. Not all of the 26 language families and approximately 100 languages investigated are shown in this graph. The graph is limited to one language per subfamily, as categorized by Glottolog (Hammarström et al., 2017).

The colors in the graph represent different strategies for forming superlatives, and the shapes represent the available interpretations for quantity superlatives. A square represents the case in which quantity superlatives have both relative and proportional readings (YES-YES). A circle indicates that quantity superlatives do not have proportional readings but do have relative readings (NO-YES). A diamond indicates that quantity superlatives have neither reading (NO-NO). ${ }^{3}$ Crucially, the map only contains these three shapes: we did not need icons for the case where the quantity superlative is used for proportional but not relative readings (YES-NO) because no such cases were attested.

Hence, the universal given in (11) 'Proportional implies relative' was supported. Proportional readings appear indeed to be typologically marked. Any language that uses the superlative of 'many' for a proportional reading also uses it for a relative reading.

Furthermore, we are now in a position to begin to estimate approximately how rare the YESYES pattern is. We cannot merely count up the number of YES-YES languages and then divide by the total number of languages, because we had a significant over-representation of Germanic languages which all have the property in question. Such a method would thus over-estimate the underlying 'natural' rate at which this occurs, as it were. We must take into account the fact that related languages are correlated data points.

We found the YES-YES pattern in 5 of the 26 language families. That is one coarse estimate of the rate. To get a more accurate estimate, we can look within each language family and calculate the rate at which YES-YES languages are found within that family. We then take the average

\footnotetext{
${ }^{3}$ Note that there is a fine line between not having a superlative of many and having a superlative of many but not using it for relative readings, but we have not been systematic about making that distinction, so the diamond category includes both languages that lack a superlative of many and languages that have one but do not use it for relative readings.
} 


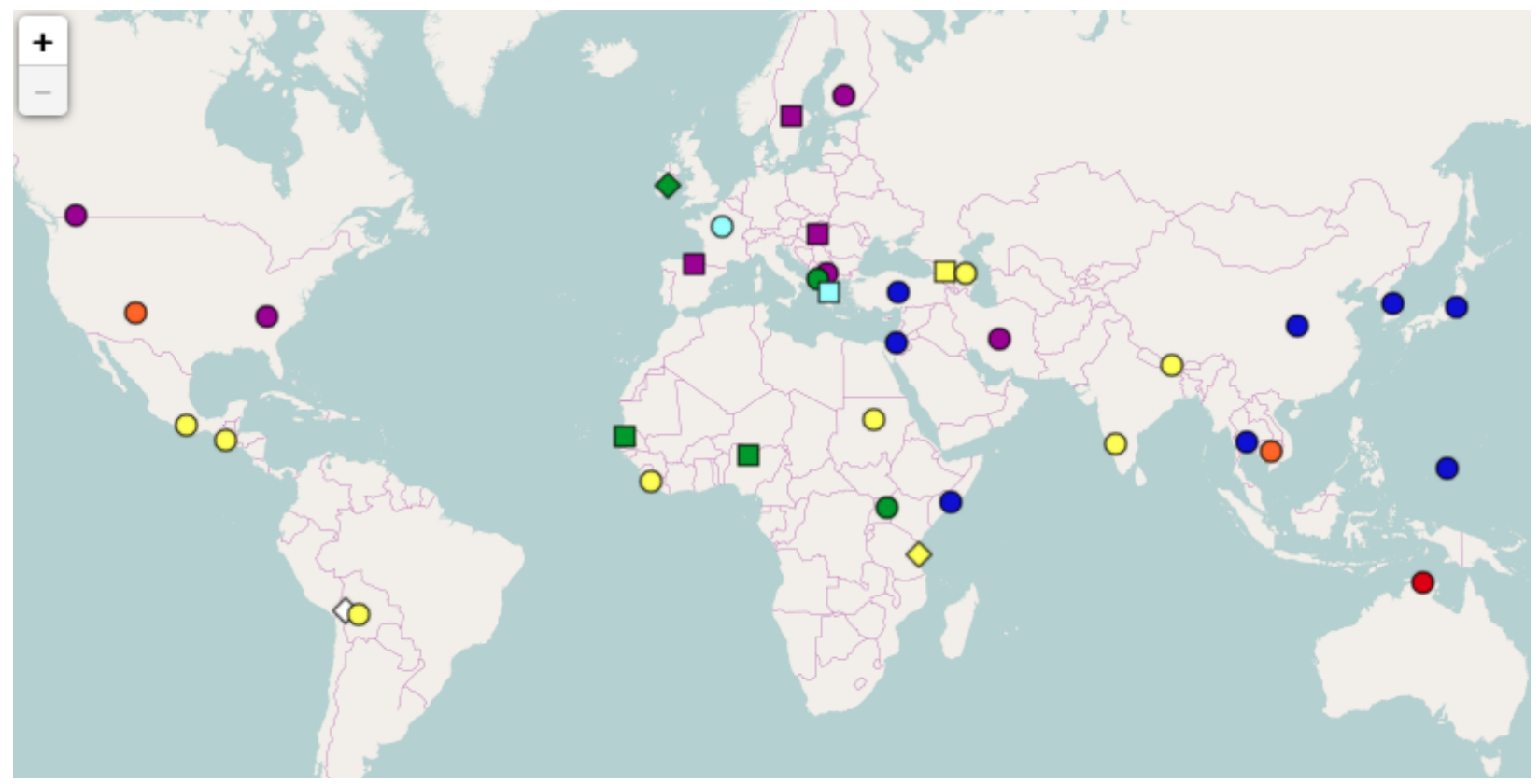

\section{Legend (colors)}

M: Morphological superlative marker

- PERIPH: Periphrastic superlative marker

O CMPR+DEF: Comparative plus definiteness marker

- CMPR: No formal distinction between comparative and superlative

O CMPR+ALL: Comparative plus 'of/than all'

O CMPR+ANY: Comparative plus 'of/than some/any'

- VERY or ABS: Intensifier

O OTHER/NONE

\section{Legend (shapes)}

- NO-YES: Quantity superlatives do not have proportional readings but do have relative ones

- YES-YES: Quantity superlatives have both relative and proportional readings

४ NO-NO: Quantity superlatives have neither

Figure 1: Representative sample of languages investigated with one language per subfamily (26 language families). Colors indicate superlative strategy; shapes indicate available quantity superlative interpretations.

rate per language family as our overall estimate. To calculate the rate for a particular family, we can look at each subfamily of the language and see whether that subfamily typically has the pattern. Indo-European has two subfamilies that typically have it, out of seven families investigated, so the rate for Indo-European would be $2 / 7$. This method yields the following calculation:

$$
\frac{2 / 7+1 / 3+1 / 2+1 / 1+1 / 2}{26} \approx 0.10
$$

Thus, using this method, we arrive at the conclusion that proportional readings arise at a rate of approximately $10 \%$. Note that there is a very great amount of uncertainty surrounding this estimate because there are approximately 4000 language families, and we only looked at 26 of them. 
Furthermore, we have not investigated most of those 26 in much depth. But these findings nevertheless do indicate that the pattern is relatively rare.

4. A closer look at the data. Let us now take a closer look at some of the data that we found. The cases where quantity superlatives are used for both proportional and relative readings exhibit a variety of strategies for forming superlatives. Table 3 lists languages that use the superlative of many for both relative and proportional readings.

Table 3: YES-YES languages

\begin{tabular}{|c|c|c|c|}
\hline M & DEF & CMPR+ALL & CMPR \\
\hline Swedish & Greek & Georgian & Hausa \\
\hline $\begin{array}{l}\text { Hungarian } \\
\text { Basque }\end{array}$ & Romanian & & Wolof \\
\hline
\end{tabular}

Table 3 does not contain many languages, but the languages it does contain exhibit a remarkable diversity. One might have expected all of the YES-YES languages to use a morphological strategy, as proportional readings might be thought to arise through a grammaticalization process that produces a quantificational determiner. But as we will illustrate below, we find proportional readings for superlatives of 'many' formed by several other strategies as well.

Nor are all of the YES-YES languages Indo-European. Basque, for example, uses a superlative strategy for all of the four types of potential readings of superlatives in question.

(18) Amak munduko gaileta goxo-en-ak egiten ditu eta.

Mom world cookie good-SPRL-PL make have and

[Basque] 'Mom bakes the yummiest cookies in the whole world [ABS].'

Ez naiz famili-an gerri estu-en-a duena.

not be family-POSS waist thin-SPRL-ART have.REL.ART

'I don't have the thinnest waist in the family [REL].'

Nire eskolara doazen haur gehi-en-ek musika jotzea atsegin dute.

my school in child much-SPRL-PL music play gladly have.3PL

'In my school, most of the kids like to play music [PROP].'

Nire eskolako haurre-tatik, ni naiz instrumentu gehi-en jotzen dituena.

my school child-among I am instrument much-SPRL play AUX

'Of the kids in my school, I'm the one who plays the most instruments [REL].'

One interesting point to notice about Basque is that for a proportional reading, as we see in (20), the superlative form of much is marked by the plural suffix '-ek', but this marker is missing in (21), which has a relative reading. So plural-marking correlates with interpretation.

Hausa is another particularly notable case. (22) shows an ordinary quality superlative on an absolute reading. 
Mama na gasa biskit din da ya-fi

(kowane) dadi a duniya.

[Hausa]

Mom my bake biscuit TOP that 3SG-exceed every delicious in world

'My mother bakes the most delicious cookies in the world [ABS].'

In this case, Hausa can choose freely between CMPR and CMPR+ALL, as kowane, a universal quantifier serving as the standard of comparison, is optional. Translating word-for-word, the two options are 'my mother bakes cookies that exceed in deliciousness in the world', or 'my mother bakes cookies that exceed everything in deliciousness in the world.'

But the universal standard is obligatorily absent in (23), expressing a proportional meaning, even though a form of the 'exceed' verb $f i$ is present:

Ma-fi yawa-n yaran dake makarantarmu suna son yin waka. NMLZ-exceed many-LINK children in school 3PL like make song 'Most of the kids in my school like to play music [PROP].'

Here, we cannot insert kowane in (23); the CMPR+ALL strategy is ruled out as a way of expressing proportional readings. Note that $m a$ in $m a-f i$ is a nominalizer, so $m a-f i$ means 'one(s) who exceed'; this may be connected to the impossibility of an explicit universal standard here.

For relative readings, our Hausa consultants often used an 'exceed' verb taking the focussed constituent as a subject.
Ba ni-ne
na-fi
kowa ramammen kur
kunkuru ba
cikin dangi-n
mu.
NEG 1SG-be.SG.M 1SG-exceed who skinny waist NEG inside family-LINK 1PL
'I'm not the one in my family with the thinnest waist [REL].'
lit. 'I do not exceed who has a skinny waist in my family.'
Fatima ta fi kowa sanin baitoci.
Fatima 3SG exceed every know verse
'Fatima knows the most verses.'
lit. 'Fatima exceeds everyone who knows verses.'

In (25), the focus of the sentence is Fatima, and the subject of the exceed verb is also Fatima.

But other strategies may also be available: we also obtained the following translation for 'Fatima knows the most verses', in which the subject of the exceed verb is not the focus (Fatima):
Fatima ta san baitoci ma-fi
yawa.
Fatima 3SG know verse NMLZ-exceed many
'Fatima knows the most verses.'

Further research is necessary in order to determine what strategies are available for the expression of relative readings, under what circumstances.

Georgian goes against the prediction that we would make in light of the fact that CMPR+ALL lacks a proportional reading in Hausa. As reported in Table 3, Georgian uses an all strategy for both relative and proportional readings. The following examples show the all strategy with quality superlatives.

(27) deda msoplioshi qkhvela-ze gemriel ortskhobilas atskhobs. mom in.the.world all-on tasty cookies bakes 
'Mom bakes the tastiest cookies in the world [ABS].'

$$
\text { chemi ojakhshi, me ar var is, visats qkhvela-ze tsvrili ts'eli ak'vs. }
$$
my family 1 be NEG it who all-on thin waist have 'In my family, I am not the one who has the thinnest waist [REL].'

This strategy can also be used for relative readings with many as in (29). Surprisingly, we also see this all-phrase qkhvela-ze with a proportional interpretation in (30).

$$
\begin{aligned}
& \text { me var chveni ojaxis wevri, romelic qkhvela-ze met namcxvars wams } \\
& \text { I am our family member who all-on many.CMPR cookies eats } \\
& \text { 'I am the member of our family who eats the most cookies [REL].' }
\end{aligned}
$$

qkhvela-ze bevri rdze modis dzrokhisgan.

all-on much milk come cow

'Most milk comes from cows [PROP].'

So apparently proportional readings can arise with the CMPR+ALL strategy.

But this is not the only respect in which our Georgian data is surprising. ${ }^{4}$ There is another one, which makes this language come very close to falsifying our hypothesis. In addition to the all strategy, Georgian can make use of a circumfix marking the predicate, as seen in (31). This circumfix is sometimes used to translate superlatives.

$$
\text { deda mtel msoflioshi u-gemriel-es namcxvrebs acxobs. }
$$
mom whole in.the.world CMPR-tasty-CMPR cookies bakes

'Mom bakes the most delicious cookies in the world.'

This strategy is very often used in combination with the word for many to give a proportional interpretation; an example is shown in (32).

\section{bavshvebis u-met'-es-oba-s, kids CMPR-many-CMPR-NMLZ-DAT ... 'Most of the kids ...'}

But this circumfix in combination with many cannot be used with relative interpretations. Here, then, is a potential counterexample: a superlative strategy that produces proportional but not relative readings.

But there is plenty of work on Georgian showing that this circumfix is not a true superlative. For example, Gippert $(1997,32)$ writes, "While formations such as $u=d i d=e s-i$ 'the greater one' (from did-i 'great, big') can easily be shown to have been primarily used as comparatives in Old Georgian, they became later confined to a superlative or elative function ('the greatest / very great one'), comparatives being substituted by analytic combinations of the plain adjective with upro 'more' (upro did-i 'the greater, more great one')." Hewitt $(1995,49)$ writes: 'The synthetic formation, which in meaning is rather neutral between comparative and superlative, employs the circumfix $u$-es-i." Harris $(2000,145)$ writes: "In Old Georgian a comparative form of the adjective was made with the circumfix u-es(i) '-er,' but in Modern Georgian this is the superlative (or

\footnotetext{
${ }^{4}$ This paper very much echoes the message of Alice Harris's presidential address at the 2017 LSA Annual Meeting (at which this paper was presented), in which she extolled the typological idiosyncrasies of Georgian.
} 
elative, not comparative." So this circumfix appears to retain some semantic features of the comparative from Old Georgian, and may be more appropriately characterized as an elative or intensi-fier than as a true superlative. If we can exclude this circumfix from the domain of our hypothesis on these grounds, then our investigation has not turned up any counterexamples to it.

5. Towards an explanation. Our study has shown that proportional readings of quantity superlatives are typologically marked, and rare. Let us consider why this might be the case.

Broadly, the answer we propose is that proportional readings require ingredients beyond just many and a superlative. In other words, those two elements alone are not sufficient to produce proportional readings. We would like to suggest, furthermore, that there are two routes to a proportional reading that a language might take. One route builds on the idea from Hackl (2009) that -est quantifies over non-overlapping pluralities. Another route builds on an idea that was first made precise by Hoeksema (1983), also advocated by Coppock \& Josefson (2015), that the comparison class is a specific binary partition.

Hackl's idea is that 'many-est' holds of any $\mathrm{x}$ that is more numerous than all $\mathrm{y}$ in the comparison class $\mathrm{C}$ which do not overlap with $\mathrm{x}$. For example, consider a $\mathrm{C}$ made up of the elements $\mathrm{a}, \mathrm{b}, \mathrm{c}$, and all sums thereof, including ab (the sum of a and b), ac (the sum of a and c), and abc (the sum of all three). Consider the question: Which of these elements satisfy the condition imposed by 'many-est'? The element $a b$ does, because the only y among all of the elements in $\mathrm{C}$ which does not overlap with $\mathrm{ab}$ is $\mathrm{c}$, and $\mathrm{c}$ has fewer atoms than $\mathrm{ab}$. Therefore, this particular $\mathrm{x}$ is more numerous than all $\mathrm{y} \in \mathrm{C}$ which do not overlap with it, and satisfies the description. Similar reasoning holds for ac and bc and of course abc. So this theory predicts that any plurality which constitutes more than half of the atoms in the domain will satisfy the condition.

This analysis thus correctly derives a proportional reading, i.e. more than half. It also predicts that the superlative of many under a proportional reading would be indefinite because there is not a unique satisfier of this predicate. That is in accordance with the fact that proportional most in English is not accompanied by a definite determiner. In Icelandic, one can see clearly that the superlative of most is morphologically indefinite (e.g. flestir krakkana 'most of the boys'; Coppock under review). So that kind of view might work for English and Icelandic. But it would not work for languages like German, Dutch, Swedish, and Hungarian, where definiteness-marking is used with a proportional reading (e.g. die meisten Kinder 'most of the kids' in German).

An analysis based on Hoeksema's idea would predict the definiteness-marking we see in languages like German. Hoeksema retains an ordinary analysis of -est without Hackl's overlappingness condition. For Hoeksema, a given element of $\mathrm{C}$ is $\mathrm{G}$-est if it is more $\mathrm{G}$ than any distinct element of $\mathrm{C}$ (as opposed to any non-overlapping element of $\mathrm{C}$ ). In the case of a proportional reading, the atoms in the domain are divided into two groups, of which one is bigger than the other, so the comparison class is a particular partition over the atoms. For example, the comparison class might consist of just $\mathrm{ab}$ and $\mathrm{c}$. This assumption correctly predicts that the superlative of many is definite on a proportional interpretation, for languages like German.

This reasoning depends of course on the assumption that the definiteness-marking that we see in languages like German is not only meaningful but also associated with the noun phrase as a whole rather than a subconstituent. In each particular case, it is necessary to do a close analysis of the language in question to determine the constituency structure, and determine how the 
noun phrase in question behaves semantically. ${ }^{5}$ We lack the space here to motivate either one of these analyses for any particular language; we merely lay them out as two possible routes that a language might take in order to produce a proportional reading, i.e., two possible additional ingredients that a language might use, above and beyond 'many' and the superlative.

6. Conclusions and future work. Aside from the critical case of Georgian, we have supported the proposed universal, repeated in (33).

\section{Proposed Universal: Proportional $\Rightarrow$ Relative}

If a superlative form of 'many' or 'much' has a proportional interpretation, then it also has a relative interpretation.

In more concrete terms, we found languages where the superlative of 'many' or 'much' had a relative reading but no proportional reading (NO-YES languages), and languages where both readings were attested (YES-YES languages), languages where neither was attested (NO-NO languages), but no languages where the superlative of 'many' or 'much' had a proportional reading but no relative reading (YES-NO languages).

The case of Georgian motivates us to refine the proposed universal slightly. The hypothesis in (33) is intended to apply regardless of the strategy used for forming superlatives, and we explicitly included the intensifier strategy (VERY) among the possible strategies for forming superlatives. So strictly speaking, the Georgian case could be seen as a counterexample; the circumfix could be seen to count as a superlative despite being an intensifier. But there is a reasonable perspective from which this type of case ought not to count. An intensifier is quite different in nature from a superlative. It doesn't have the same implication of uniqueness, for example; there may be several women who are extremely brilliant, but only one most brilliant woman. So there is an important sense in which an intensifier does not have the same meaning as a superlative. But requiring that the construction 'have the same meaning' risks rendering the hypothesis too weak, because it could be argued that even the CMPR+ALL strategy does not have the same meaning as an English superlative, at some fine-grained level. So what is needed is a principled criterion, based on a sufficiently coarse-grained notion of 'having the same meaning', which separates out intensifiers while including a non-trivial range of strategies for forming superlatives.

Our results nevertheless support the conclusion that proportional readings do not fall out directly from the combination of a quantity word with a superlative. We have suggested that there are two routes to a proportional reading, one that is based on an idea from Hackl (2009), and one from Hoeksema (1983). The former predicts no definiteness-marking (as in Icelandic) and the latter predicts definiteness-marking (as in German).

There are many complicating details that this proposal does not take into account, and many questions for further research. For example: Why do proportional readings involve a plural quantity word in Basque? Does the 'exceed' verb always take the focus as the subject in relative readings in Hausa? What is the role of the nominalizer in Hausa? (A number of other languages also use nominalizers in the expression of quantity, including Lezgian.) Why is the CMPR+ALL strategy ruled out with proportional readings in Hausa but allowed in Georgian? What rules out relative readings with the u-es circumfix in Georgian? This is just a sampling of the questions that arise from the data we have presented; the data we have collected presents many more.

\footnotetext{
${ }^{5}$ Thanks to Rajesh Bhatt for discussion of this point.
} 
As we have seen, there exists great diversity in the morphosyntactic strategies used to express superlative meanings crosslinguistically, and quantity superlatives are even more richly diverse. It is remarkable that in the midst of all of this diversity, a linguistic universal could emerge. But this appears to be what we have found. Relative readings appear not to require any extra ingredients beyond a quantity word and a way of indicating a superlative interpretation, while proportional readings require something more.

\section{A. Appendix: Translation questionnaire.}

Instructions. Please translate the sentences below into your native language. More literal translations are preferred, but only as long as they sound natural. Give as many translations as you like, and comments are welcome but not required. (No need to translate the parts in parentheses; they are just supposed to help explain what is meant.)

1. Most of the kids who go to my school like to play music. (For example, there are 100 kids in my school, and 65 of them like to play music.)

2. Of all the kids in my school, I'm the one who plays the most instruments. (For example, I play 7 instruments, two of my friends play 6 instruments, and lots of people play one or two instruments, but nobody else plays more than 4.)

3. I don't like most of the music they play on the radio.

4. My brother Hans also plays many instruments, but not more than me.

5. The member of my family who plays fewest instruments is my sister Karin.

6. During most of the summer we have played music every day.

7. I don't know how much coffee we've drunk and how many cookies we've eaten during the summer.

8. But it is probably Hans who has drunk the most coffee. (For example, Hans drank three cups every day, and the rest of us drink one or two cups every day.)

9. Mom says that he ought to drink less coffee.

10. I am the one who drinks the least coffee.

11. But I am also the member of our family who eats the most cookies. (For example, I eat on average 5 cookies per day, and other members of my family eat on average 4 or fewer cookies per day.)

12. Mom baked cookies yesterday and I ate most of them. (For example, she baked 20 cookies and I ate 14.)

13. I drank most of the milk too. (For example, there were two liters of milk and I drank 1.5 liters.)

14. I'm not the one in the family with the thinnest waist.

15. I ought to eat fewer cookies.

16. But it's hard since mom bakes the yummiest cookies in the whole world.

17. Many try, but few can resist mom's cookies!

\section{References}

Bobaljik, Jonathan David. 2012. Universals in comparative morphology: Suppletion, superlatives, and the structure of words. Cambridge, MA: MIT Press. 
Bochnak, Ryan. 2015. The degree semantics parameter and cross-linguistic variation. Semantics \& Pragmatics 8(6). 1-46.

Coppock, Elizabeth. under review. Quantity superlatives in Germanic, or, life on the fault line between adjective and determiner. Journal of Germanic Linguistics .

Coppock, Elizabeth \& David Beaver. 2014. A superlative argument for a minimal theory of definiteness. Semantics and Linguistic Theory (SALT) 24, 177-196. https://doi.org/10.3765/salt.v24i0.2432.

Coppock, Elizabeth \& Christian Josefson. 2015. Completely bare Swedish superlatives. In Eva Csipak \& Hedde Zeijlstra (eds.), Proceedings of Sinn und Bedeutung 19, 179-196. University of Göttingen.

Dobrovie-Sorin, Carmen \& Ion Giurgea. 2015. Quantity superlatives vs. proportional quantifiers: A comparative perspective. Abstract for 25th Colloquium on Generative Grammar, Bayonne.

Gippert, Jost. 1997. The formation of comparatives in the history of georgian. part ii: The syntactical development of comparative constructions within the history of the georgian language. In Helma van den Berg (ed.), Studies in caucasian linguistics: Selected papers of the eighth caucasian colloquium, 32-44. Leiden: Leiden University.

Gorshenin, Maksym. 2012. The crosslinguistics of the superlative. In Cornelia Stroh (ed.), Neues aus der bremer linguistikwerkstatt - aktuelle themen und projekte, 55-159. Bremen: Brockmeyer.

Hackl, Martin. 2009. On the grammar and processing of proportional quantifiers: most vs. more than half. Natural Language Semantics 17. 63-98.

Hammarström, Harald, Robert Forkel \& Martin Haspelmath. 2017. Glottolog 3.0. Jena: Max Planck Institute for the Science of Human History. http: / / glottolog . org.

Harris, Alice. 2000. Word order harmonies and word order change in Georgian. In R. Sornicola, E. Poppe \& A. Sisha-Halevy (eds.), Stability, variation, and change of word order patterns over time, 133-163. Amsterdam: John Benjamins.

Haspelmath, Martin. 1993. A grammar of Lezgian. Berlin / New York: Mouton de Gruyter.

Hewitt, George B. 1995. Georgian: A structural reference grammar. Amsterdam: John Benjamins.

Hoeksema, Jack. 1983. Superlatieven. TABU 13(101-106).

Pancheva, Roumyana \& Barbara Tomaszewicz. 2012. Cross-linguistic differences in superlative movement out of nominal phrases. In Nathan Arnett \& Ryan Bennett (eds.), Proceedings of WCCFL 30, 292-302. Somerville, MA: Cascadilla Press.

Stassen, Leon. 1985. Comparison and universal grammar. Oxford: Blackwell.

Szabolcsi, Anna. 1986. Comparative superlatives. In Naoki Fukui, Tova Rapoport \& Elizabeth Sagey (eds.), Papers in theoretical linguistics, 245-265. Cambridge, MA: MITWPL.

Teleman, Ulf, Staffan Hellberg \& Erik Andersson. 1999. Svenska Akademiens grammatik [The Swedish Academy Grammar], vol. 1-4. Stockholm: Svenska Akademien/Norstedts.

Živanović, Sašo. 2006. Varieties of most: On different readings of superlative determiners. In Proceedings of of the 2006 Formal Description of Slavic Languages (FSDL 6.5) conference, 337-354. University of Nova Gorica. 